MedieKultur | Journal of media and communication research | ISSN 1901-9726

Article

\title{
Interviewing media workers
}

\section{Heike Graf}

MedieKultur 2010, 49, 94-107

Published by SMID | Society of Media researchers In Denmark | www.smid.dk The online version of this text can be found open access at www.mediekultur.dk

The focus of this article is on the use of Niklas Luhmann's systems theoretical approach in order to analyse interviews conducted with media workers concerning their experiences of ethnic diversity in newsrooms. Applying systems theory means constructing the interview as a social system and seeing the "data" as observations produced by the observer and not as representations of a reality. The first part of the article describes the interview methodology and the second part provides examples, from the current study, of how systems theory can be applied in order to analyse interviews. Using a difference-theoretical approach means looking at the distinctions the informants make when talking about their experiences. These main guiding distinctions can be summarised as immigrant background/competence as well as advantage/competence. Using the guiding distinction of inclusion/exclusion when interpreting the interviewees' statements, the interdependencies of mechanisms of inclusion and exclusion in newsrooms related to ethnic background can be examined.

\section{The observer-related perspective: Distinctions}

A research interview defined as a self-referential interaction system (Luhmann, 1984, pp. 551- 592) is, according to the systems theory developed by Niklas Luhmann, a complex social system of, in an observer-related terminology, contextures. Contextures are realities in which the world appears as contexts and for which the observer is the origin of these con- 
textures (Nassehi \& Saake, 2002, p. 81). Therefore, a systems theoretical approach demands a perspective in which the observer (the interaction system, the person) is the originator of that which is observed and communicated in the interview.

Traditionally, we might speak of descriptions in terms of representations: we perceive an event and describe it more or less exactly according to the event. That would mean the event precedes the narrative. The systems theoretical approach, however, speaks of distinctions that precede narratives or take precedence over the descriptions (Rasch, 2002, p. 23). With this approach, the originator of the description, or the observer, comes into play when analysing the narrative, by coupling the narrative to the observer, because observing means drawing distinctions. According to observation theories (e.g., Spencer-Brown, 1969; von Foerster, 1984; Luhmann, 1997), it is by noting a difference that one becomes aware of things and creates meaning. In other words, one can only observe something if it is different'. If we do not notice a difference nothing can be observed. The notions of "observer" and "observation" greatly differ from everyday language, which means we make distinctions and describe them.

In order to determine how meaning is constructed in the interviews, we can use the difference-theoretical approach developed by the mathematician George Spencer-Brown (1969). In his work on formal logics, Spencer-Brown pointed out that we cannot describe anything without drawing distinctions: We notice one side of the distinction at the expense of the other, to which we pay less attention. This is necessary if we want to gain knowledge about the side in which we are interested. If we ascribe equal value to both sides, "knowledge of everything has become knowledge of nothing" (Spencer-Brown, 1969/1997, p. 192).

Again, a distinction does not describe a phenomenon; it does not describe, e.g., the newsroom as it is. It describes a form of it, and it describes this form from the perspective of the observer. The emphasis, however, is not on how the two sides of the distinction differ from each other, but on the difference itself. The two sides are connected to each other as different parts and as such they create a unit. In this sense, the form always includes what is excluded, i.e., the other side of the form. Every use of a distinction (e.g., in the interview statements) excludes other possibilities. Even if the distinction makes the alternative possibility explicit, it still excludes those that it does not make explicit (Nassehi \& Saake, 2002, p. 71). The researcher must therefore always deal with the unobserved, that is, not only with what is the case, but also, and particularly, with what is not the case (Nassehi \& Saake, 2002, p. 70). The researcher obtains data which must be read in the light of the data that is excluded, as the meaning of the included is determined from the perspective of what is excluded (Nassehi \& Saake, 2002, p. 75).

If we apply a difference-theoretical approach to newsrooms studies, we have to admit that we cannot say anything about the ontology of newsrooms. We can only say something about the relationship of the observer to the observed, that is, the relationship of the interviewee to an addressed topic. The topic of my research question is the following: how do journalists with migrant backgrounds experience their recruitment, working con- 
ditions and career possibilities within German media organisations? Traditionally, when doing newsroom research, one wants to know how the newsroom really works; and in the current case, whether the media organisations respond to the challenges of the culturally diverse society or not. Methodologically, we conduct interviews and include participating observations to eliminate the shortcomings of the interview method, and we believe we reached an authentic understanding of the newsroom reality. According to la Cour et al. (2005), the "systems theoretical interview", however, is not understood as a representation of a phenomenon outside the observer, but as a construction, that is, as a product of observation which is contingent (la Cour et al., 2005, pp. 11, 13). According to Luhmann, each observation refers to a "self" as well as an "other" (see, e.g., Luhmann, 1997); therefore, we can only say something about the other-reference, that is, the media organisation, if we place the observation in relation to the self-reference of the interviewee in an interview situation.

As mentioned above, this systems theoretical approach greatly differs from a representation logic that is examining the adequacy of an object. This kind of logic, often confused with construction approaches, can also be found in the (Nordic) standard work of research interviews, such as saying: "The qualitative research interview seeks to understand the world from the perspective of the interviewee, to develop meaning from the interviewee's experiences, and to reveal the actual world the interviewee inhabited prior to the scientific explanations" (Kvale \& Brinkmann, 2009, p. 17, my translation and italics). Alternatively, and from the same source, "the qualitative research interview is a unique opportunity to access and describe the lived everyday world" (Kvale \& Brinkmann, 2009, p. 44, my translation and italics).

The systems theoretical approach distinguishes itself from that approach by overcoming ontology, by introducing a difference between system and environment as a starting point of the theory. Concerning the above paragraph, we can speak of the distinction between an event, that is, e.g., a newsroom situation, and a description, which is generally deduced. Consequently, the order of descriptions is not determined by the event, but by further distinctions that guide descriptions, for which I intend to give examples from my case study later.

Traditionally, when interviewing we want to know "why the interviewee feels and acts in the way he/she does" (Kvale \& Brinkmann, 2009, p. 46, my translation and italics). From the systems theoretical point of view, however, we have no access to another reality, that is, another consciousness' feelings and intentions; we only have the descriptions, and cannot know why that which is expressed is described in one way, and not another. Even intrusive questions from the interviewer does not give more real or better information, instead we gain insight into the strategy of how the interviewee deals with intrusive questions (Nassehi \& Saake, 2002, p. 80). This difference-theoretical approach has consequences for the analysis, and, therefore, it is useless to speculate on the reasons or causes for something being described in a particular way. That means we cannot answer "why" questions, in contrast to 
what is claimed concerning the standard work of conducting interviews. On the contrary, the systems theoretical approach demands that we have to move from "why" to "how" questions when analysing interviews.

Realising that observations are observer related helps us to overcome the methodological shortcomings derived from ontological approaches that aim to reveal the "real world" as "objective" as possible.

\section{The guiding distinction of the analysis}

In order to interpret the interviews, as a researcher I have to make clear the distinctions guiding my observation, which can be seen as an observation of the observations of the interaction system interview (second-order observation ${ }^{2}$ ). My guiding distinction has to be a distinction which is open to multi-contextual perspectives, and the distinction of inclusion/exclusion fills this function. I did not choose the distinction discrimination/equality (as was done in studies by, e.g., Nohrstedt \& Camauër, 2006), because this distinction is used in a moralising manner (good/bad); it includes too many normative statements. The distinction inclusion/exclusion, however, is used as a cognitive distinction and not a normative one. It denotes a person's general participation, or non-participation, in the communication that - in the current case - takes place within media organisations. To illustrate this, generally, most people are excluded from media organisations (like other organisations), which is neither a good nor a bad thing. However, if we state that most people are discriminated within media organisations, we would judge it as negative. Another example would be if an informant says that he is excluded from a job because of turn-taking, that could, on the one hand, be bad for him, but, on the other hand, it could be good in regard to respecting the rules of the organisation. This distinction of exclusion/inclusion allows different observer perspectives and, therefore, more options and combinations in the analysis of the material. As a result, the strength of this approach is its multi-dimensionality when meeting the observed empirical "data". By contrast, employing the distinction discrimination/equality would restrict the complexity of the interviews from the very beginning, as the intention would be to focus only on those distinctions that are observed as wrongfully drawn (see also Hellman, 2008).

According to Rudolf Stichweh (2005, p. 60), the distinction of inclusion/exclusion is a hierarchical rather than a binary, "either-or" opposition. One of the two sides can be a generic term. To illustrate this, Stichweh uses an example culled from Foucault. In prison, a convict is excluded from society, but is, at the same time, exposed to prison mechanisms that are meant to include and reintegrate the convict into society after the sentence has been served (Stichweh, 2005, p. 62). My informants provide several examples, which I will discuss later, of how inclusion can accompany exclusion, and how this constitutes a dynamic process. As stated by Stichweh (2006, pp. 135-136), there are two general mechanisms that include individuals: the mechanism of situation, which names or addresses persons, and 
the mechanism that forms structures through expectations. Inclusion and exclusion are defined by performance roles that are based on certain expectations. Where exclusion is concerned, the excluded individual is not being addressed, and nothing is expected of that person.

I can make this point clearer by using the example of the National Integration Plan initiated by the German government in 2007. This plan utilises the situation mechanism: saying that journalists of migrant background should be integrated in media production, means that they are addressed and should participate in communication within media organisations. The Plan also uses the structure-forming mechanism: expectations of individuals are expressed by saying that editorial staff members of migrant backgrounds have first-hand knowledge about immigration issues, and therefore can report competently on integration issues (Der Nationale Integrationsplan, 2007, pp. 159-160). Strictly speaking, a migrant background almost automatically connotes expert knowledge of intercultural matters. This expectation of being an expert on integration issues can lead to forms of both inclusion and exclusion, should the person not live up to this expectation. The emphasised difference (that is, that migrant journalists are experts on immigrant issues) might be situational and temporary, and, in that case, would not contribute to the development of lasting inequalities. But if the effects of these differences accumulate, lasting inequalities can arise (Stichweh, 2005, p. 171). I will return to this point in connection with the statements of my interviewees.

\section{The analysis: The reality of the interview responses}

I started the process of the analysis by noting the different patterns of the interviewees' responses ${ }^{3}$, based on migrant backgrounds and topics of recruitment, job conditions and career. As mentioned above, in interview communication, there are descriptions, whose meanings are generally created by a plenitude of references and conclusions. Hence, I looked at how these references meet and form patterns in a fabric (Vogd, 2005, p. 66) of the individual observation strategies. Because I interviewed a number of media workers (21 journalists), I can compare their different answers and use this comparison as a methodological key. When comparing different cases, the common characteristics, differences, contingencies and dependencies of the fabric become clear. This creates a pattern that is subsequently discussed in different contexts. To find patterns that connect to other patterns is part of the difference-theoretical analysis, the purpose of which is to show how observers create structures in their meaning-production processes (Vogd, 2005, p. 26). Therefore, the difference-theoretical analysis makes it possible to transcend the individual case and offer generalisations (Vogd, 2005, p. 78).

By pointing out the distinction patterns, I have noticed there are observation structures without connection to migrant background, and ambivalences are articulated in relation to other contextures, for example, educational background, market economy or organisa- 
tional structure. By comparing the individual semantic difference schemes of those who make references to a migrant background, I find that many distinctions could be summarised by the common pattern characterised by the distinction of migrant background and competence, which can be observed as an advantage or a disadvantage to the media worker. In retrospect, it is not very surprising to find the distinction of competence/lack of competence, since these are people who are describing their working conditions (and not leisure time, e. g.).

There are also other distinctions that I cannot put under the umbrella of the semantic distinction of advantage/disadvantage. For instance, when talking about coverage of topics, some self-selected forms of exclusion have occurred, which are neither an advantage nor a disadvantage. One informant does not report on a special ethnic conflict topic because he feels too emotionally involved in it due to his origin. Another informant of Asian origin, who feels insecure when meeting a small group of neo-Nazis, excludes himself from reporting on the issue for safety reasons. These distinctions differ from the main patterns in so far as they are exclusions that have been made by the informants themselves and that have not been forced on them through expectations. They make a conscious choice of not covering specific topics that are related to their backgrounds.

In the following sections, I will illustrate the four main patterns apparent in communication concerning recruitment, working conditions and career possibilities. In summary, migrant background is seen as:
1) an advantage and part of competence
2) an advantage and lack of competence
3) a disadvantage and lack of competence
4) making no difference.

A fifth general pattern of "disadvantage/part of competence" does not occur in the material, because those who observe migrant origin as intrinsic to competence generally describe their experiences in newsrooms as positive and not as disadvantaged. If they discuss coverage of topics, they express comfort over certain narrow topics (related to migration issues), if they reflect on career setbacks, they attribute them to the general market and job conditions rather than to ethnic origin. Thus, if migrant background is observed as part of competence, the media worker feels included, and addresses (forced) exclusions in relation to something other than ethnic background.

\section{1) Migrant background as an advantage and part of competence}

As of April 2007, Dunja Hayali, who is of Iraqi origin, co-anchors the prime-time news show on the German public broadcasting network ZDF. She is the first co-anchor-person with a migrant background. According to an article published on the Deutsche Welle website, it 
was no secret that the German broadcasting network ZDF had been looking for a presenter with a migrant background. The article quotes Hayali as saying:

Of course my qualifications were the most important criterion, but there's no denying my immigrant background was an added plus in bagging the job. (Phalnikar, 2007)

ZDF was looking for a presenter who was of obvious immigrant origin, and who could play the role of integrating immigrants. For that role, a blonde woman with blue eyes would not do. In this case, a visible migrant background functions as an inclusion mechanism. Another journalist stresses also the advantage gained by her origin when covering certain topics:

To be a freelance journalist with a migrant background is not at all bad. If I offer a story to an editorial staff about an integration topic that fits my knowledge about Turkey, I sell it immediately. It is automatically assumed that I have higher intercultural competence. (Ataman, 2007)

Having a migrant background pays off. Here, a reference to the market economy is made. Irrespective of whether ethnicity makes a person an expert or not, he or she will use it as a means of getting ahead; what counts are commonly-held expectations. If as a freelancer one lives up to this common expectation, one has the advantage of being included in journalistic work when selling topics and seeking employment. Another female journalist confirms the common expectation when pointing out her accumulated and actual knowledge, as well as the contacts she has within her own ethnic group:

I know the weak points of my community, [...] or what a tricky topic is. I know the rights and also the problems of the immigrants from my own experience. I already know how to treat the topic. [...] I can handle it better than my German colleagues. (Woman, radio, R4)

Having more experience of different cultures in one's own life means, for her, having a greater awareness of different modes of intercultural communication. As she is also endowed with intercultural competence, the journalist feels better suited to handle immigrant issues. Another example of this can be seen concerning the topic of language skills. Language issues focus mainly on a bilingual or multilingual person's opportunities and difficulties when it comes to handling the German language. In this case, having a non-German mother tongue is observed as an advantage in written language. It may provide a means by which one's written German can be improved: 
I think that if one works with languages, and has lived abroad for a long time, one has a greater chance of enriching them. [... ] I still sometimes write commentaries interspersed with [Nationality] and [Nationality] idioms and proverbs. And when I translate them into German, or experiment with them, it makes my German language style more interesting. (Woman, radio, R2)

These responses show that the informants take advantage of their migrant backgrounds by stressing their special competencies. If they can conform to common expectations, for example, being experts on migrant issues, visibly belonging to an immigrant population or having special language competence, they experience an advantage when seeking assignments and jobs, and ethnicity comes to function as an inclusion mechanism.

\section{2) Migrant background as advantage and lack of competence}

This pattern mainly emerged in connection with recruitment, and stands for the whole discussion on "token" roles as the following example shows:

I am the token Turk at [organisation]. I was employed against the will of my section head. It came entirely from above. (Man, TV, R5)

Here, the informant makes the distinction of being a "token" - a person who was awarded his position because of his ethnic background rather than his qualifications. The claim that even his direct superior, with whom he has to work most of the time, opposed his employment clearly shows (together with the expression "token Turk") his discomfort: he is included in an excluded way. The informant later adds that he has not completed his academic or professional training (although he does have journalistic experience) and therefore does not meet all the formal job requirements. But due to organisational decisions aimed at furthering the participation of journalists with migrant backgrounds, he was ranked higher than an applicant with a non-migrant background. His employers expected his knowledge of the Turkish community to compensate for his lack of formal education; they predicted he will have a special competence that the organisation requires. For this journalist, his migrant background was an advantage for getting the job, but he is observed to be lacking in corresponding competence. Here, ethnicity is explicitly including (getting the job) and implicitly also excluding by being less formally qualified than his colleagues. For him, exclusion becomes obvious when talking about career possibilities, as I will show later.

\section{3) Migrant background as disadvantage and lack of competence}

The emphasis on the "token" role, which often leads to a distinction between being competent and being incompetent, can also stress the notion of a disadvantaged ethnic background, which can lead to exclusions. I can illustrate my point with the following quote: 
It was like that at the meetings, when it came to assignments: I put my hand up three times, and no one else did that. Even so, I did not get the job even if no one else was interested in it. [...]

HG: Was this because of your migrant background?

Of course. Yes, of course. More than anything, yes. (Woman, radio, R 8)

It was during her internship, and she thought that the assignment in question would provide an excellent training opportunity. The assignment concerned a popular tourist site, nothing special or difficult; if she made mistakes, there would be no serious consequences. In this situation, however, her background led to exclusion from special assignments. She had come to Germany as an adult, and had not learned German culture from the cradle. She speaks German with a slight accent. As a non-native, she was observed to be unqualified to report on a local tourist attraction on the radio. Marking ethnicity in contrast to cultural knowledge of the majority culture, and, therefore, as a lack of competence, hints at an organisational culture that seems to legitimise inequality. The unspoken expectation may be: "you do not belong to the indigenous society, do not know all the 'secrets' and, ultimately, you are not fully qualified to report on that society." Here, ethnicity functions as an excluding mechanism, one that serves to prevent a particular group of people from covering special topics.

Another female interviewee provides an additional example of an exclusionary mechanism based on ethnicity. This woman, who has been in the media business for more than fifteen years, explains that while there may be exceptional cases like Hayali's, in general, little has changed:

When I started in TV, I was told that I had better leave it [....] 'We prefer blondes'. Of course they did not say it to my face. That happened only once. During the casting - off the record - someone recommended that I become an author, behind the camera. The time is not yet ripe for such exotic 'cases' as me. (Woman, TV/ radio, R6)

This journalist feels she is being labelled as someone who does not correspond to the competence profile of a TV presenter because of her appearance. This is to her disadvantage. A print journalist of Asian origin tells a similar story. During his internship at several media organisations, his teacher had tried to talk him out of attempting a career as a TV presenter, citing his Asian origin as the reason. TV producers expect a presenter who conforms to the established visual standard of a (German) presenter. This is a typical mechanism for exclusion with respect to features such as appearance. This exclusion seems to be more than situational and temporary. It is a general exclusion, one which leaves the excluded with only one option: to assume a role behind the camera or as a relatively "invisible" person in radio or print media. Here, lasting inequalities have arisen. 
Another example comes from the topic of career possibilities:

Presently, my career has come to somewhat of a halt. It is always said that more immigrants should work in the media. The situation is like this: there is more demand for people in front of the cameras than in executive positions. We have not come so far yet; but I hope I will experience that. [...]. That people have enough confidence that somebody with twentyfive years of experience in journalism or fifteen years of management experience can also move on to a higher position. (Man, radio, R1)

This man's experience is that the trend of recruiting journalists with migrant backgrounds extends only to lower-level positions in the hierarchy, and to "visible" immigrant news presenters. Having a migrant background means for him having less managerial competence, which in turn prevents the executives from giving more responsibility to experienced immigrant journalists. An inability to make career advances is related to the organisational contexture, which he observes as resisting change. A migrant background is seen as a barrier to career advancement, and, therefore, as an exclusion mechanism.

\section{4) Migrant background as making no difference}

This pattern has emerged in connection with all the topics discussed and is expressed both explicitly and implicitly. Career pauses and opportunities are not exclusively related to the issue of ethnicity. For interviewees who are generally satisfied with their careers, which means that they observe their migrant backgrounds as a "plus" and contributing to their competence, ethnicity does not make a difference. There are, for example, pauses that are attributed to general organisation requirements such as training issues or internal career ladders, or even organisational culture issues, such as the following three quotes indicate:

\footnotetext{
I have already advanced a lot in my career. It is not easy to become a presenter on TV. But if I want to join the first league in a public service organisation, I have to possess a university degree. I don't. (Man, TV, R5)
}

He will not advance in his career until changes occur. He may graduate, he may move to another organisation, or the organisation may change its requirements. The next quote, from another journalist, shows that ethnicity can lose some of its function as an explanation for the interviewee's missing promotion: 
When the [broadcasting station] several times refused to send me to [city] as a correspondent, I thought I was unsuitable because I had too little distance to the topics, due to my ethnic background. At the time I thought so. But now I do not believe in that explanation. It has to do with the internal career ladder, and it was not my turn. [...] That kept me busy for a time because it was a pity. If it was because of my background, it would have meant that I never can do that, or I have to wait until they have forgotten that I am a [nationality].

(Man, radio/TV, R3)

Here, the informant reflects on whose fault it is that he did not get the job. With time, the informant changes his observation strategy (guiding distinctions) and stops attributing the setback to himself, that is, his own lack of competence. Instead, he starts blaming the organisation. This shift of blame towards the organisation's formal structure strengthens his desire to continue his journalistic career. His distinction shift, from competence to pecking-order or turn-taking, makes it possible for him to hope to be considered for the position at some future time. A female journalist attributes setbacks in her career to an organisational culture that is observed as hierarchical and less tolerant toward critical comments and questioning, which leads to exclusion from career possibilities:

I would not blame my migrant background for all. I am a fighter and not everyone likes that. I often comment on things, I discuss, I want to have clarified things and I absolutely do not acknowledge hierarchies when I feel that is nonsense. Therefore it certainly has something to do with my personality. (Woman, press, R13)

\section{Conclusions}

In this article, my focus has been on analysing interview responses from the differencetheoretical approach by asking how the notion of ethnic background generates differences in interviewees' meaning-construction processes (and how not). Analysing interviews in the light of systems theory means relating the interview statements to the observer by marking the distinctions guiding their descriptions. This method is not aimed at analysing causal relations, but at illuminating latent structures and functions of the observation strategies, and it clarifies the preferred relational observation patterns when communicating an issue. Thus, the method does not simply copy or duplicate the viewpoint of the informants; but it does undergo a process of both reduction and an increase of complexity, which is not observable for the informants themselves in the communication process (Luhmann, 1984, p. 88).

The analysis can, therefore, appear more complex than it is for the interviewee him/herself; and with it can portray an issue such as migrant background in newsrooms, in the light of different possibilities. Migrant backgrounds do not simply mean being disadvantaged and discriminated against, as stated in Camauër (2006), but appear - in the light of systems 
theory - as a complex issue. In other words, this approach is strongly empirically oriented; it analyses the observation strategies developed by the interviewees themselves. More precisely, it demands an approach that does not prejudge before studying the material, and is therefore open for the contingency, that is, that everything could have been observed in a different way.

By using guiding and cognitive distinctions (such as inclusion/exclusion), rather than normative distinctions, when analysing the interview statements, prejudgment is avoided and it is possible to look at the issue from different angles. The interdependence, or in other words, complexity, becomes visible, which although a strength of this approach is also a great challenge. Applying such an approach allows one to go beyond the individual interview responses by finding interconnections and therefore strategies (guiding or established distinctions) in meaning-construction processes.

From the empirical data I could distinguish the main guiding distinction of competence/ advantage that my informants drew in relation to migrant background, and which generally characterise their preferred relational observation strategies. How stable these guiding distinctions are is hard to say; only the repetition of the interviews with the same people at another time might provide more insight on this. These communicated observations constitute a reality that devises the narratives in one way rather than another way. It is not about whether one really is competent or not or has advantage or not, but a distinction guiding the narratives communicated in the interview. Here, the observers (the interviewee, the interviewer, the interview as interaction system) re-enter the reality and can be considered in the analysis; which is the main difference regarding other non-constructive approaches.

To summarise, the constructed reality of the interviews statements indicates that a migrant background generates difference in meaning-production processes by coupling it with competence. More precisely, the established distinctions restrict contingency of the possible answers in this way, i.e., having a different ethnic background can be observed as an advantage to the media worker if he or she can fulfil common expectations. It is a disadvantage when these expectations are not fulfilled. Here, more or less subtle mechanisms of inclusion and exclusion occur. Exclusions can be attributed to a different ethnic origin, but also to structural constraints or other communicative problems within media organisations. When ethnicity is brought into play, the difference between being sufficiently or insufficiently competent is important when describing recruitment and job conditions, as well as career. Ethnicity can be intrinsic to competence, and it can even be described as a "plus"; and/or it can be part of incompetence, and observed as a "minus".

Interviewees who experience a lack of competence can observe their background as an advantage when being recruited (see the "token" discussion). However, the disadvantage comes into play when discussing job conditions and career opportunities. In this respect, more attention is paid to the issue of migrant background. Consequently, the newsroom culture is observed as being characterised by expectations which may restrict journalists with migrant backgrounds to certain narrow topics - those related to migration and inte- 
gration issues, and to some secondary positions in the organisation. Migrant journalists feel excluded from a wide range of topics, as well as from jobs on screen. In this context, ethnicity functions as a mechanism for legitimising inequalities.

In conclusion, the difference pattern of being acknowledged (or not) as a competent media worker with migrant background is decisive for informants' observation strategies of advantage and disadvantage in newsrooms.

\section{References}

Ataman, F. (2007). "Du bekommst bestimmt einen Job". Journalistik Journal, 27. september 2007. Retrieved December 15 2007, from http://journalistik-journal.lookingintomedia.com/?p=59.

Camauër, L. (2006). Mediearbetare med utländsk bakgrund och majoritetsmediers diskrimineringsmekanismer. In Nohrstedt, S. A. \& Camauër, L., Mediernas vi och dom: mediernas betydelse för den strukturella diskrimineringen ( $p$ p 35-88). Stockholm: Fritze.

Der Nationale Integrationsplan. Neue Wege - neue Chancen (2007), Retrieved May 20 2008, from http:// www.bundesregierung.de/Content/DE/Archiv16/Artikel/2007/07/Anlage/2007-07-12-nationaler-inte grationsplan, property=publicationFile.pdf.

Hellman, D. (2008). When is discrimination wrong?. Harvard: University Press.

Kvale, S. \& Brinkmann, S. (2009). Den kvalitativa forskningsintervjun. Lund: Studentlitteratur.

La Cour, A., Knudsen, M. \& Thyge Thygesen, N. (2005). Det systemteoretiske interview: Interviewet som meningsdannelse. Copenhagen Business School: Department of Management, Politics and Philosophy. Retrieved January 12 2010, from http://openarchive.cbs.dk/bitstream/handle/10398/6428/wp8-2005. pdf? sequence $=1$.

Luhmann, N. (1984). Soziale Systeme. Grundriss einer allgemeinen Theorie. Frankfurt a. Main: Suhrkamp.

Luhmann, N. (1997). Die Gesellschaft der Gesellschaft. Bd.1, Frankfurt a. Main: Suhrkamp.

Nassehi, A. \& Saake, I. (2002). Kontingenz: Methodisch verhindert oder beobachtet?. Zeitschrift für Soziologie, 31,1, 66-86.

Nohrstedt, S. A. \& Camauër, L. (2006). Mediernas vi och dom: mediernas betydelse för den strukturella diskrimineringen. Stockholm: Fritze.

Phalnikar, S. (2007). New Face on German TV Highlights Dearth of Minority Presenters. Retrieved April 20 2008, from http://www.dw-world.de/dw/article/0,,2456173,00.html.

Rasch, W. (2002). Introduction: The self-positing society. In Luhmann, N., Theories of distinction. Redescribing the descriptions of modernity (Ed. William Rasch) (pp 1-30). Stanford: Stanford University Press.

Spencer-Brown, G. (1969). Laws of Form. London: George Allen and Unwin Ltd.

Stichweh, R. (2005). Inklusion und Exklusion. Studien zur Gesellschaftstheorie. Bielefeld: transcript.

Vogd, W. (2005). Systemtheorie und rekonstruktive Sozialforschung. Eine empirische Versöhnung unterschiedlicher theoretischer Perspektiven. Opladen: Barbara Budrich.

Von Foerster, H. (1984[1960]). Observing systems. 2. ed. Seaside, Calif.: Intersystems Publications. 


\title{
Notes
}

1. As an example, if I walk in a park and smell a lilac tree, I probably look for the tree. I have observed the difference between the lilac fragrance and all the other smells and things in the park. I could have missed the smell and the tree altogether. I could also have perceived something else. Other people, perhaps, do not smell this tree, do not notice it, and have thus not observed it.

2. The conducted interview can be understood as first-order observation. Not until the second-order observation do we become aware of how things are described.

3. My selection of journalists was done by using the distinction of migrant contra native: He or she is different from a native because $s /$ he has, e.g., a foreign citizenship or has parents of a foreign origin. The selection of interviewees was done according to the snowball principle. Nevertheless, my interviewee group consists of a good mixture of age, gender, first- and second-generation immigrants, permanently employed and freelancers, and of different cultural backgrounds. A total of twenty-one journalists with migrant backgrounds, ten women and eleven men, between 25 and 55 years old (with an average age of 38) were interviewed in Berlin during May, September and October 2007, and April and November 2008. Nine of these are employed on permanent contracts; the remainder are on fixed-term contracts or are freelancers. Half of them work at the Press. Only one has a management position (editor in chief) at a radio station. Nine were born and partially trained in a foreign European country. They are first-generation immigrants. The other interviewees are second-generation immigrants; they were born and raised in Germany. Most of those who are employed on permanent contracts in German mainstream media are first-generation immigrants. All but three obtained degrees in journalism, or some other academic field, in their home countries. Ten of my interviewees have a Turkish background, and three a Russian background. The others have Middle-Eastern, Northern and Southern European, North-African, Latin-American and Asian backgrounds.

\author{
Heike Graf \\ Associate professor \\ Media and Communication Studies \\ Södertörn University, Sweden \\ Heike.Graf@sh.se
}

